\title{
Nanoencapsulation of Nisin and Ethylenediaminetetraacetic Acid in Niosomes and Their Antibacterial Activity
}

\author{
P. Kopermsub*, V. Mayen, and C. Warin \\ National Nanotechnology Center, National Science and Technology Development Agency, Klong 1, \\ Klong Luang, Pathumthani, 12120, Thailand
}

Received 7 January 2012, accepted in revised form 18 March 2012

\begin{abstract}
Ethylenediaminetetraacetic acid or EDTA was used complementarily with nisin to give a synergistic antibacterial effect against Gram positive and negative bacteria. Nisin and EDTA were encapsulated in nonionic surfactant vesicles or niosomes. Sorbitan monooleate and polyethylene glycol were precursors in preparation of niosomes. Size reduction of niosomes was conducted via extrusion through polycarbonate membrane with pore size of $200 \mathrm{~nm}$. Diameters of prepared blank niosomes and nisin-EDTA-encapsulated niosomes were approximately $130 \mathrm{~nm}$ and $270 \mathrm{~nm}$, respectively. Bilayer structure of niosomes was observed from negative staining-transmission electron microscopic images. Long-termed investigation of antimicrobial activity of nisin-EDTA-encapsulated niosomes and free nisin/EDTA were conducted against Staphylococcus aureus and Escherichia coli. Bacterial counts denoted a slow release of nisin-EDTA-encapsulated niosomes overtime whilst free nisin/EDTA gave a sudden bactericidal activity. Due to that free nisin/EDTA was immediately exploited at the beginning, bacterial counts then tended towards higher during the latter time of antimicrobial activity test.
\end{abstract}

Keywords: antibacterial; EDTA; Escherichia coli; niosomes; nisin; Staphylococcus aureus.

(c) 2012 JSR Publications. ISSN: 2070-0237 (Print); 2070-0245 (Online). All rights reserved.

doi: http://dx.doi.org/10.3329/jsr.v4i2.9407 J. Sci. Res. 4 (2), 457-465 (2012)

\section{Introduction}

Contamination of food pathogens in animal feeds and foods has been a major concern in the distribution and storage of the products worldwide [1, 2]. Among various preservations, biopreservation using natural derived compounds is more preferable compared to synthetic chemicals [3]. Nisin (Food Additive, E234) is one of bacteriocins derived from Lactococcus lactis which has long been used as an antimicrobial substance and is recognized in food and pharmaceutical applications [4]. Nisin, a 34-amino acid polypeptide, attacks bacterial cell via the complex formation between nisin and the lipid II molecule, a bacterial cell wall synthesis precursor located in bacterial cell membrane. The formation of the complex results in a pore formation across plasma membrane and a rapid outflow of small cytoplasmic compounds which causes cell death [5]. Nisin exhibits

\footnotetext{
* Corresponding author: phikunthong@nanotec.or.th
} 
strong bactericidal and sporostatic activities against Gram positive bacteria. Whereas bactericidal activity of nisin against Gram negative bacteria is limited due to an inaccessibility of nisin to plasma membrane. Ethylenediamine tetraacetic acid or EDTA, a metal chelating agent is supplemented into the system containing bacteria and nisin in order to broader antibacterial spectrum of nisin [6]. EDTA binds with metal cation such as $\mathrm{Mg}^{2+}$ and $\mathrm{Ca}^{2+}$ localizing in an outer membrane of Gram negative bacteria. This results in a destabilization of the outer membrane and allows an accessibility of nisin to peptidoglycan [7].

Most part of nisin (>90\%) remains intact after autoclave treatment condition at $121^{\circ} \mathrm{C}$, 15 min, $\mathrm{pH}$ 3.0-3.5. However, its activity, stability, and degradation also depend on factors such as $\mathrm{pH}$, salt content, protease enzymes which are capable of nisin activity inactivation. Using nisin in food system as a free form diminishes its activity and stability due to nonspecific binding of antimicrobial molecule with lipid or protein molecules and presence of enzymes in food matrix. Controlled release and stability enhancement of encapsulated nisin using liposome, a lipid bilayer system were reported by several authors [8-11]. Applying liposome as an encapsulated shell material has several significant drawbacks including high cost of phospholipids, high susceptibility to oxidative degradation, and sedimentation of fused liposomes during storage. In food application area, nonionic surfactant vesicles or niosomes are considered as a good candidate to be used as an encapsulated shell material because of its low cost of surfactant material compared with expensive liposome materials. Several classes of nonionic surfactant are used in preparation of niosomes such as polyglycerol alkyl ethers, glucosyl dialkylethers, crown ether and polyoxyethylene alkyl ether and esters [12]. Sorbitan monooleate as known as Span 80 is a biocompatible nonionic surfactant species in a group of oxyethylene alkyl esters. It is approved to be used as an emulsifier or dispensing agent in food applications. The hydrophilic-lipophilic balance (HLB) number of span 80 is 4.3 which considerably low to form stable bilayer vesicles. Polyethylene glycol (PEG) is supplemented in the solution system to increase HLB and allow a formation of stable bilayer vesicles.

The work presented here is an elucidation of antibacterial activity of nisin-EDTAencapsulated niosome against model Gram positive and negative bacteria. The niosome was easily prepared with a simple formulation, $\operatorname{span}^{\circledR} 80$ and PEG by basic extrusion method. Long-termed antibacterial activity test against Staphylococcus aureus and Escherichia coli was conducted in order to observe activity difference between free nisin/EDTA and encapsulated nisin/EDTA.

\section{Materials and Methods}

\subsection{Materials}

Sorbitan monooleate or Span $80 \AA$, PEG 400, and nisin were bought from Sigma-Aldrich (St. Louis, MO, USA). Ethylenediaminetetraacetic acid was bought from Ajax Finechem Pty Ltd (Australia). Bacterial strains Escherichia coli (ATCC 25922) and Staphylococcus aureus (ATCC6538) were obtained from the Department of Medical Sciences, Ministry of Public Health, Thailand. 
Nisin stock solution was prepared by dissolving nisin powder in $0.02 \mathrm{~N} \mathrm{HCl}$ and then filtered through 0.2 micron cellulose acetate membrane and stored at $-80^{\circ} \mathrm{C}$ until used. Span $80 \AA$ stock solution was prepared in absolute ethanol and then filtered through 0.2 micron cellulose acetate membrane and stored at $4^{\circ} \mathrm{C}$.

\subsection{Minimum inhibitory concentration}

Minimum inhibitory concentration (MIC) of nisin and EDTA against E.coli and S.aureus was evaluated by a checkerboard microassay in a 96-well plate. Tested concentration of nisin and EDTA used were 256, 128, 64, 32, 16, and $8 \mu \mathrm{g} / \mathrm{ml}$; and 4000, 2000, 1000, 500, 250 , and $125 \mu \mathrm{g} / \mathrm{ml}$, respectively. All of the experiments were carried out in duplicate. Plate was incubated at $37^{\circ} \mathrm{C}$ for $24 \mathrm{~h}$. The MIC was defined as the lowest concentration of nisin and EDTA combination that inhibits the visible growth of test bacteria after overnight incubation.

\subsection{Preparation of niosomes}

Formulation and method of niosomes preparation were modified from the method described by Hua and Liu [13]. Span $80^{\circledR}$ concentrated stock was prepared by dissolving Span $80^{\circledR}$ in absolute ethanol. Niosomes solution was prepared using Span $80^{\circledR}$ and phosphate buffer (pH 8.0) at the ratio of 0.003:99 (by weight) and 1\% (w/w) of PEG 400. The solution was vigorously mixed and thereafter extruded through a polycarbonate membrane with a nominal pore size of $200 \mathrm{~nm} 20$ times using a Lipex extruder (Northern Lipids Inc., Vancouver, Canada). For nisin-EDTA-encapsulated niosomes, the same formulation of niosome solution was used with an addition of nisin and EDTA into niosome solution before extrusion through a polycarbonate membrane.

\subsection{Antibacterial activity}

Escherichia coli and Staphylococcus aureus in tryptic soy broth (TSB, Difco Laboratories, Germany) were incubated at $37^{\circ} \mathrm{C}$ for $16-20 \mathrm{~h}$. Bacterial cell suspension was diluted using Mueller-Hinton broth in order to obtain an approximate final concentration of $10^{6} \mathrm{CFU} / \mathrm{ml}$. E. coli or S. aureus suspension was thoroughly mixed with the test sample including: (i) free nisin-EDTA, (ii) nisin-EDTA-encapsulated niosomes; and (iii) blank niosomes, (iv) phosphate buffer $\mathrm{pH} 8.0$ as control at the volume ratio of 10:10. This manner made a decrease in final concentration of nisin and EDTA by half (final concentration at 8 and $125 \mu \mathrm{g} / \mathrm{ml}$, respectively) in all samples containing nisin and EDTA. The duplicate samples were incubated at $37^{\circ} \mathrm{C}$. Samples were taken at certain time during incubation and analyzed for bacterial count using spread plate technique.

\subsection{Encapsulation efficiency}

Nisin and EDTA molecules encapsulated in niosomes were separated from free nisin and EDTA molecules by Amicon ${ }^{\circledR}$ Ultra-4 10K (Millipore S.A., France). Encapsulated nisin 
and EDTA were released from niosome vesicles by adding $1 \%$ final concentration of Triton-X 100. Nisin and EDTA released from vesicles were quantified by HPLC. Determination of nisin and EDTA by HPLC was conducted according with Salmaso and colleagues [14], and modified method of Venezky and Rudzinski [15], respectively.

\subsection{Size analysis}

The size of niosomes was measured based on dynamic light scattering (DLS) technique using Zetasizer Nano ZS (Malvern Instruments Ltd., United Kingdom). The parameters for measurement and calculation were set as followed: $173^{\circ}$ backscatter measurement angle, 1.33 material refractive index, $25^{\circ} \mathrm{C}$, and water as a dispersant. Each sample was measured 3 times in clear disposable zeta cell. Number of run and run duration were optimized for each sample in order to obtain result meeting measurement quality criteria.

\subsection{Negative staining-transmission electron microscopy}

Morphology of blank niosomes and niosomes containing nisin and EDTA were analyzed by negative staining-transmission electron microscopy (NG-TEM). Sample was dropped onto a Formvar-coated 300 mesh copper grid and was leaved for $1 \mathrm{~min}$. The grid was rinsed with deionized water for 3-5 sec. and stained with $1 \%$ uranyl acetate solution for 1 min. Prepared sample was visualized by transmission electron microscope (JEM-1220, Jeol Ltd., Japan)

\section{Results and Discussion}

\subsection{Characterization}

Niosomes containing nisin and EDTA had an approximate size of $266 \mathrm{~nm}$ which considerably bigger compared with $130 \mathrm{~nm}$ in size of unloaded or blank niosomes. Regarding niosomes composition containing Span 80®: Phosphate buffer ( $\mathrm{pH}$ 8.0) ratio at 0.003:99 (by weight), the encapsulation efficiency of nisin and EDTA were considerably low at $11.38 \%(\mathrm{w} / \mathrm{w})$ and $0.1 \%(\mathrm{w} / \mathrm{w})$, respectively. The encapsulation efficiency of niosomes prepared in this study was lower than the average value previously reported from our group [16]. The distinction may due to the amount of nisin and EDTA used for loading and formulation of niosomes itself. The images of blank and nisin-EDTAencapsulated niosomes were shown in Fig. 1. Fresh niosome sample without prior staining and drying was visualized by $100 \mathrm{X}$ magnification of differential interference contrast mode microscope (Olympus BX-50, Olympus, Japan). Only minute variation in niosome size was observed from fresh niosomes. By NS-TEM, niosome particle on copper grid was rarely discovered which incomparable with the number of fresh niosome particles elucidated in Fig. 1 (a). This may due that step in preparation of NG-TEM made fragile niosome particle broken. Size of blank and nisin/EDTA encapsulated niosomes calculated from TEM were approximately at $660 \mathrm{~nm}$ and $228 \mathrm{~nm}$, respectively. These size data were 
dissimilar to size measurement by dynamic light scattering using Zetasizer Nano. Practically, size data of sensitive nanoparticle obtained from TEM cannot be used for interpretation of population actual size due to low number of particle available and distortion of particle structure from TEM-sample preparing condition. In this study, bilayer-structure of niosome was illustrated from NS-TEM images which identical to bilayer-structure of nisin-encapsulated liposome observed by confocal laser microscopy [10].

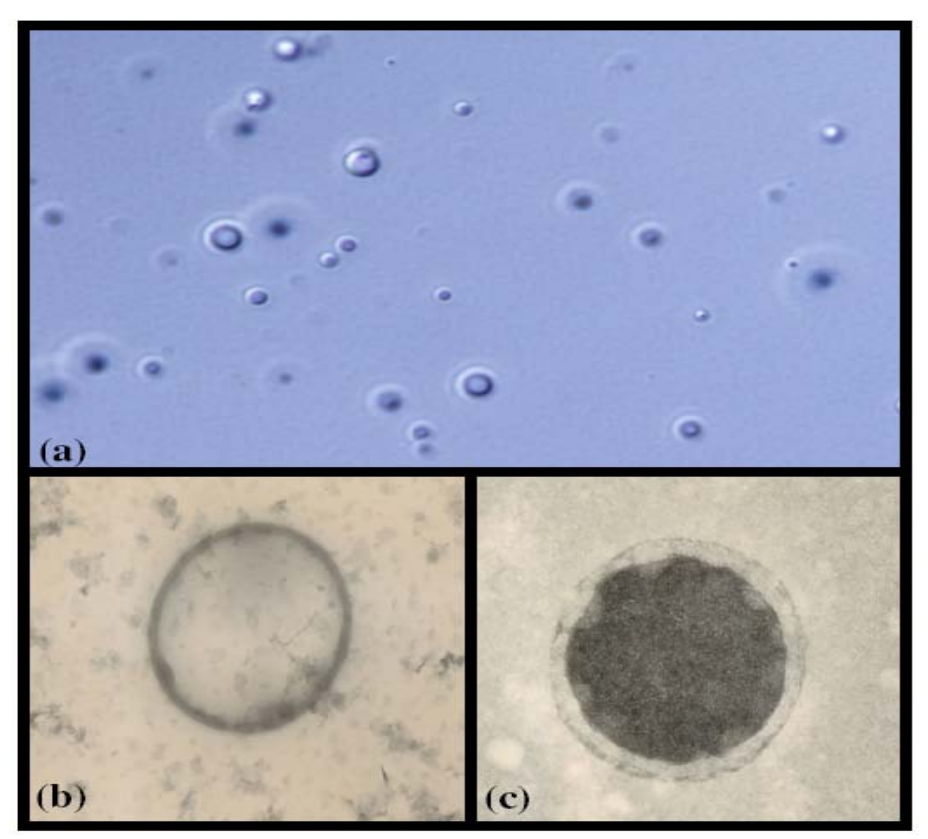

Fig. 1. Niosomes images: (a) niosomes micrograph, (b) NG-TEM images of blank niosome (ca. 660 $\mathrm{nm}$ ); and (c) nisin-EDTA-encapsulated niosome (ca. $228 \mathrm{~nm}$ ).

\subsection{Antibacterial activity}

From MIC determination, at all combination of nisin and EDTA was found to inhibit growth of S.aureus. This is due to that nisin could access to cytoplasmic membrane of S.aureus, a Gram-positive bacteria and subsequently form pores with Lipid II without protection from an outer layer membrane which presents in a Gram-negative bacterium [5]. The lowest nisin concentration which found to inhibit E.coli growth was $16 \mu \mathrm{g} / \mathrm{ml}$ when used complementarily with $250 \mu \mathrm{g} / \mathrm{ml}$ EDTA. In this study, nisin at $16 \mu \mathrm{g} / \mathrm{ml}$ and EDTA at $250 \mu \mathrm{g} / \mathrm{ml}$ were then used in encapsulation and tested against S.aureus and E.coli. Noteworthy, the final concentration of nisin and EDTA in test media was reduced by half after mixing with 1 Vol. of bacterial suspension. This allowed an observation of bacterial number change overtime instead of killing all bacteria. 

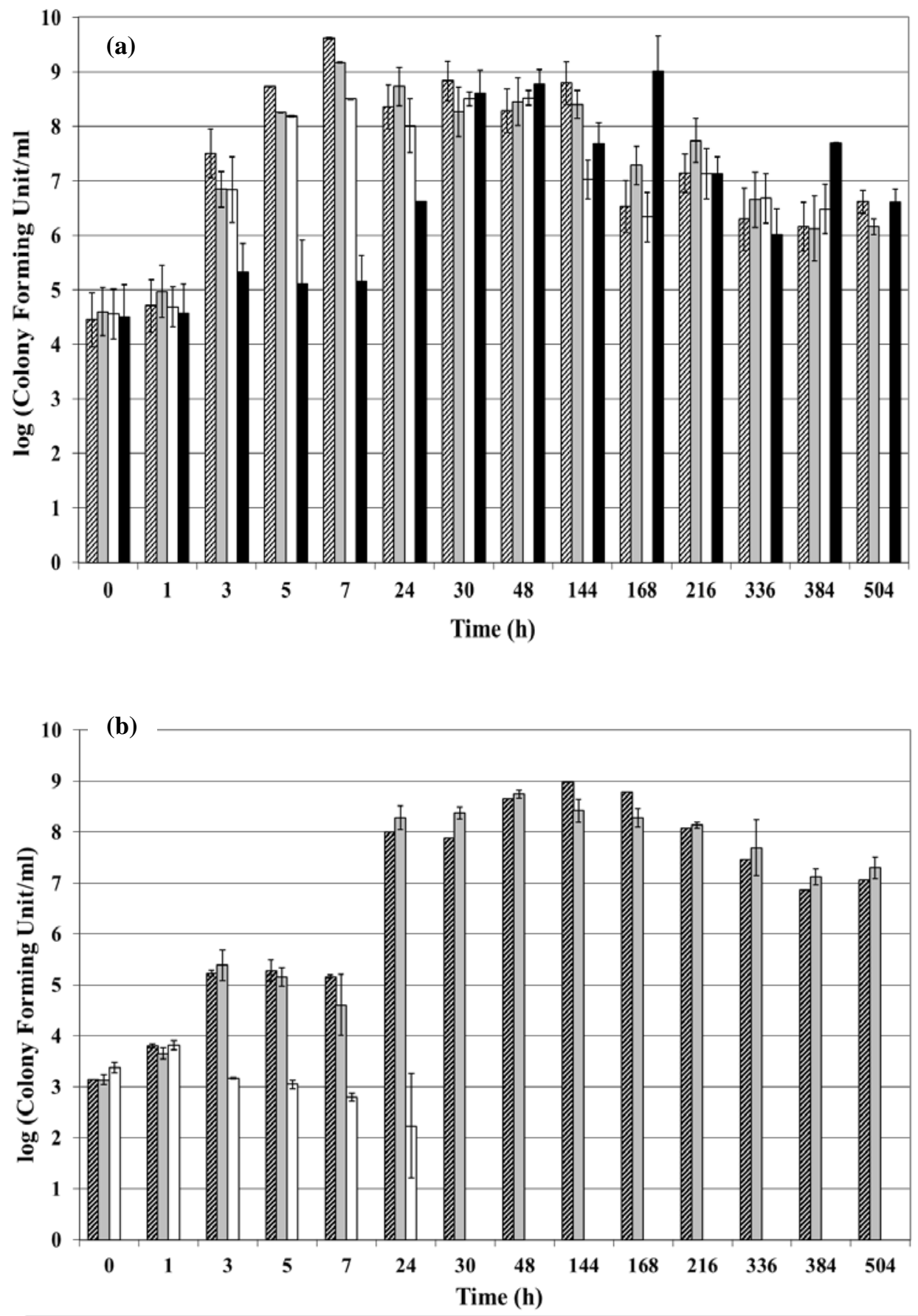

$\nabla$ Control $\quad$ B Blank niosome $\quad \square$ Nisin-EDTA-encapsulated niosome $\quad$ Free-nisin-EDTA

Fig. 2. Antibacterial activity test against (a) E.coli; and (b) S.aureus. 
Typical growth curve pattern of log, stationary phases were observed in control condition containing phosphate buffer and blank niosomes inoculation condition (Fig. 2a and $2 \mathrm{~b}$ ). Whereas death phase was not found as if incubation time was continue for $504 \mathrm{~h}$. In fact, a long-termed incubation of bacteria in batch culture creates a nutrient shortage, bacteria can however continue their multiplication indefinitely for many months. The explanation of this is that a part of bacterial population with the growth advantage in stationary phase (GASP) phenotype is be able to mutate from their parents and therefore be able to confront with the nutrient shortage environment as reported in E.coli bacterial model [17]. Nutrient availability is concurrently addressed in this experiment since its alteration had a great effect on bacterial number of long-term batch incubation.

Free nisin/EDTA (un-encapsulated form) showed an instantaneous antibacterial effect or burst release-liked effect to S.aureus after mixed them with bacterial suspension $(0 \mathrm{~h})$. The antibacterial activity of free nisin/EDTA was assumably not to occur instantaneously after mixing even though S.aureus was undetectable at $0 \mathrm{~h}$. In contrary, they may continue their activities during a process of bacterial counting (serial dilution of sample and plate incubation) since bacterial cells were not separated from test media. In all samples taken after $0 \mathrm{~h}$ of incubation, S.aureus was completely killed by free nisin/EDTA. On the other hand, E.coli which is a Gram-negative bacterium can withstand free nisin/EDTA better than S.aureus as its cell numbers remained comparable with control condition at 0 and $1 \mathrm{~h}$ of incubation. A gradual decrease in number of E.coli during 3-7 hours of incubation suggested an availability of nisin/EDTA in the suspension. As an amount of nisin or EDTA depleted, numbers of E.coli dramatically increased at $24 \mathrm{~h}$ before entering stationary phase.

Encapsulated nisin/EDTA exhibited different inhibitory pattern compared with free nisin/EDTA. Encapsulated nisin/EDTA gradually released overtime which resulted in a "lower and longer" antibacterial activity pattern. In order to apply nisin-EDTAencapsulated niosomes as a food preservative, higher concentration of nisin and EDTA is adjustable to obtain effective and optimum antibacterial activity. In addition, size of niosomes also had an effect on an antibacterial activity pattern or release pattern of nisin and EDTA. The bigger size of encapsulated niosomes $(\sim 1 \mu \mathrm{m})$ exhibited rapid release rate whereas the smaller size $(\sim 50 \mathrm{~nm})$ exhibited sustained release rate.

The different inhibitory pattern between free nisin/EDTA and encapsulated nisin/EDTA was readily observed in case of S.aureus. While none of S.aureus cannot be detected since $0 \mathrm{~h}$ of incubation with free nisin/EDTA, S.aureus number gradually decreased and undetectable after $30 \mathrm{~h}$ of incubation with encapsulated nisin/EDTA. Our previous report of niosomes prepared with Span $80^{\circledR}$ with sodium stearoyl lactate and PEG400 showed a controlled release effect against S.aureus but lacking of an absolute killing effect over $72 \mathrm{~h}$ of incubation [16]. The encapsulated nisin/EDTA formulated in this study hence showed a better performance as it can kill S.aureus at $30 \mathrm{~h}$.

An antibacterial against E.coli revealed the same different pattern between free nisin/EDTA and encapsulated nisin/EDTA. During the latter stage of incubation with free nisin/EDTA, E.coli number tended to be higher compared with nisin-EDTA-encapsulated niosomes. This due to that free nisin/EDTA was used up during the initial stage of incubation whereas nisin/EDTA gradually released from niosomes throughout the 
incubation period.

The different antibacterial activity pattern between free nisin/EDTA and encapsulated nisin/EDTA complies with previous reports $[9,10,18,19]$. This study demonstrates an alternative simple, cheap, safe, and effective carrier other than liposomes for slow controlled release of nisin and EDTA.

\section{Conclusion}

Controlled release of nisin/EDTA can be manipulated by nano-sized niosomes encapsulation. The preparation of niosomes using $\operatorname{span}^{\circledR} 80$ and PEG through extrusion process is considerably cheap and simple. The nisin-EDTA encapsulated niosomes demonstrated a slow releasing rate against both model Gram negative and positive bacteria. Effective nisin/EDTA concentrations in spatial food applications and releasing rate and interaction in food models are comprehensively investigated further.

\section{Acknowledgement}

This research was financially supported by the National Nanotechnology Center, National Science and Technology Development Agency, Thailand (NN-P-51-13).

\section{References}

1. A. Chowdhuri, A. Iqbal, M. Giasuddin, and A. A. Bhuiyan, J. Sci. Res. 3, 403 (2011). doi:10.3329/jsr.v3i2.7128

2. J. A. Flint, Y.T.Van Duynhoven, F. J. Angulo, S. M. DeLong, P. Braun, M. Kirk, E. Scallan, M. Fitzgerald, G. K. Adak, P. Sockett, A. Ellis, G. Hall, N. Gargouri, H. Walke, and P. Braam, Clin. Infect. Dis. 41, 698 (2005). http://dx.doi.org/10.1086/432064 PMid:16080093

3. T. Masud and K. Anwaar, Pakistan J. Nutr. 1, 20 (2002).

4. L. J. de Arauz, A. F. Jozala, P. G. Mazzola, and T. C. V. Penna, Trends Food Sci. Technol. 20, 146 (2009). http://dx.doi.org/10.1016/j.tifs.2009.01.056 PMid:21299575

5. S. T. D. Hsu, E. Breukink, E. Tischenko, M. A. G. Lutters, B. de Kruijiff, R. Kaptein, A. M. J. J. Bonvin, and N. A. J. van Nuland, Nat. Struct. Mol. Biol. 11, 963 (2004). http://dx.doi.org/10.1038/nsmb830

6. K. A. Stevens, B. W. Sheldon, N. A. Klapes, and T. R. Klaenhammer, App. Environ. Microbiol. 57, 3613 (1991). PMid:1785933 PMCid:184021

7. L. Leive, Biochem. Biophys. Res. Commun. 21, 290 (1965). http://dx.doi.org/10.1016/0006-291X(65)90191-9

8. R. Laridi, E. E. Kheadr, R. O. Benech, J. C. Vuillemard, C. Lacroix, and I. Fliss, Int. Dairy J. 1, 325 (2003). http://dx.doi.org/10.1016/S0958-6946(02)00194-2

9. L. M. Were, B. Bruce, P. M. Davidson, and J. Weiss, J. Food Protect. 67, 922 (2004). PMid:15151228

10. J. C. Colas, W. Shi, V. S. N. M. Rao, A. Omri, M. R. Mozafari, and H. Singh, Micron. 38, 841 (2007). http://dx.doi.org/10.1016/j.micron.2007.06.013 PMid:17689087

11. T. M. Taylor, B. D. Bruce, J. Weiss, and P. M. Davidson, J. Food Saf. 28, 183 (2008). http://dx.doi.org/10.1111/j.1745-4565.2008.00113.x

12. I. F. Uchegbu, and S. P. Vyas, Int. J. Pharm. 172, 33 (1998). http://dx.doi.org/10.1016/S0378-5173(98)00169-0

13. W. Hua, and T. Liu, Colloids Surf. A. 302, 377 (2007). 
http://dx.doi.org/10.1016/j.colsurfa.2007.02.068

14. S. Salmaso, N. Elvassore, A. Bertucco, A. Lante, and P. Caliceti, Int. J. Pharm. 287, 163 (2004). http://dx.doi.org/10.1016/j.ijpharm.2004.09.003 PMid:15541923

15. D. L. Venezky and W. E. Rudzinski, Anal. Chem. 56, 315 (1984). http://dx.doi.org/10.1021/ac00266a050

16. P. Kopermsub, V. Mayen, and C. Warin, Food Res. Int. 44, 605 (2011). http://dx.doi.org/10.1016/j.foodres.2010.12.011

17. S. E. Findel, and R. Kolter, Proc. Nat. Acad. Sci. U.S.A. 96, 4023 (1999). http://dx.doi.org/10.1073/pnas.96.7.4023

18. R. O. Benech, E. E. Kheadr, C. Lacroix, and I. Fliss, App. Environ. Microbiol. 68, 5607 (2002). http://dx.doi.org/10.1128/AEM.68.11.5607-5619.2002 PMid:12406756 PMCid:129882

19. R. O. Benech, E. E. Kheadr, R. Laridi, C. Lacroix, and I. Fliss, App. Environ. Microbiol. 68, 3683 (2002). http://dx.doi.org/10.1128/AEM.68.8.3683-3690.2002

PMid:12147460 PMCid:124053 